\title{
Contextual Interference Effect Depends on the Amount of Time Separating Acquisition and Testing
}

\author{
Jefferson John dos Santos, Flavio Henrique Bastos, Thiago de Oliveira Souza, \\ Umberto Cesar Corrêa
}

School of Physical Education and Sport, University of São Paulo, São Paulo, Brazil

Email: umbertoc@usp.br

Received 11 March 2014; revised 11 April 2014; accepted 18 April 2014

Copyright (C) 2014 by authors and Scientific Research Publishing Inc.

This work is licensed under the Creative Commons Attribution International License (CC BY).

http://creativecommons.org/licenses/by/4.0/

(c) (1) Open Access

\begin{abstract}
Considering the critical role permanence has on predictions related to the contextual interference effect, this study sought to determine whether the manifestation of the effect depends on the time interval separating the acquisition phase (AQ) from the retention test (RT). Four groups of blocked (BL) and four groups of random practice (RD) performed 90 trials of a dart throwing task (AQ) and were tested exclusively after 10 minutes (BL10 and RD10), 24 hours (BL24 and RD24), 7 days (BL7 and RD7) or 30 days (BL30 and RD30). In the $A Q$, blocked groups performed three blocks of trials, with each block consisting of throwing the darts from one of three distances ( $2 \mathrm{~m}$, $2.6 \mathrm{~m}$ and $3.2 \mathrm{~m}$ ). For the random groups, the trial order was pseudo-randomized. The results indicated superior performance of RD24, compared to BL24, but no difference was found between the groups tested after 10 minutes, 7 days or 30 days. Thus, our results do not support the notion that higher contextual interference promotes immediate learning benefits nor long-term retention of internal representations. Nevertheless, future research should further investigate the processes underlying the contextual interference effect, since short-term gains ( $24 \mathrm{~h})$ were found.
\end{abstract}

\section{Keywords}

Motor Learning; Practice Schedule; Dart Throwing, Retention Test

\section{Introduction}

Reducing the amount of time taken to learn a motor skill or enhancing the adaptability and/or the permanence of its internal representation is among the main issues concerning motor learning. In the search for these favorable 
learning outcomes, researchers have been striving to better understand the Contextual Interference Effect, one of the most investigated topics in Motor Learning (Barreiros, Figueiredo, \& Godinho, 2007 for a review).

The Contextual Interference Effect refers to a random practice schedule-varying tasks, or parameters of a given task, so that the learner would not perform consecutive trials in the same condition-yielding better learning than a blocked practice schedule-performing all trials of a given task, or parameters of that task, consecutively. The assumed superiority of random practice has been based on two main hypotheses: (a) elaboration and distinction (Shea \& Morgan, 1979; Shea \& Zimny, 1983) and (b) action plan reconstruction (Lee \& Magill, 1983, 1985). According to the former, random practice would lead the learner to compare task variations, increasing the similarities and differences between them in memory. This process would occur during the interval between trials and would allow the learner to formulate a more precise representation of the motor skill. In turn, the action plan reconstruction hypothesis states that random practice would increase the cognitive effort, since the information about a particular task would be forgotten completely or partially-because of contextual interference-leading to the necessity of reconstructing action plans in subsequent trials instead of repeating a preexisting one.

Both explanatory hypotheses suggest that random practice demands greater involvement of the learner in cognitive processes, leading to a stronger internal representation of the skill being learned (Corrêa \& Tani, 2005). The memory structures originated from random practice (traits, operational representations, or plans) would be more elaborate and organized, less dependent on the initial context, and more resistant to forgetfulness, when compared to those originated from blocked practice (Lee \& Magill, 1983, 1985; Lee \& Weeks, 1987; Shea \& Wright, 1991; Wright, 1991; Wright, Li, \& Whitacre, 1992). Considering specifically this last feature, one of the main expected effects of practicing a motor skill under high contextual interference is the permanence, over time, of the capability for moving. Thus, it seems reasonable to suppose that a performance difference between groups undergoing high and low contextual interference could be better observed after an "adequate" period of time. Even though the contextual interference effect is still subject of much research (e.g. Boutin \& Blandin, 2010; Kantak, Sullivan, Fisher, Knowlton, \& Winstein, 2010; Naimo et al., 2013; Porter \& Magill, 2010; Wu et al., 2011; Yanci, Reina, Los Arcos, \& Camara, 2013), Barreiros et al. (2007) pointed out that, by the time, only 42\% of the studies were able to observe the effect. These unclear results have driven researchers to investigate whether the effects of contextual interference on motor skills learning would be dependent on factors such as task complexity (e.g. Albaret \& Thon, 1998; Ollis, Button, \& Fairweather, 2005; Silva, Araujo, Tani, \& Corrêa, 2009; Souza, Santos, Torriani-Pasin, \& Corrêa, 2013), ecological validity (e.g. Massigli, Nunes, Freudenheim, \& Corrêa, 2011; Travlos, 2010; Wrisberg \& Liu, 1991) and stage of learning or level of experience (e.g. Guadagnoli \& Lee, 2004). Considering the importance permanence has on predictions related to the contextual interference effect, it is surprising that the amount of time separating the acquisition phase from the retention test has not been given much attention.

Although not aiming to investigate this issue, Moreno et al. (2003) conducted an experiment in which three types of throwing were practiced (in blocked and random schedules) and retention tests were carried out 48 hours, 4 weeks and 8 weeks after a period of practice-13 sessions of 90 practice trials, over 3 weeks. Groups undergoing blocked and random practice schedules were tested in both blocked and random schedules. Because no significant difference was found between groups, regarding any retention interval or combination between practice and testing schedule, neither the employed time intervals nor possible implications concerning consecutive retention tests were discussed.

In the present study we sought to investigate whether the manifestation of the contextual interference effect depends on the time interval between the end of the acquisition phase and the retention test. The level of contextual interference was manipulated through the practice schedule-blocked or random. Four groups, in each of these two conditions, practiced a dart throwing task during an acquisition phase and were tested after a $10 \mathrm{mi}-$ nutes, 24 hours, 7 days or 30 days interval. The expected result was that the groups undergoing random practice would show better performance-compared to the groups undergoing blocked practice-only in latter retention tests, indicating that higher levels of contextual interference builds up more permanent internal representations.

\section{Method}

\subsection{Participants}

One hundred forty-four college students (88 men and 56 woman, $M_{\text {age }}=21.9$ years; $S D=3.2$ years) participated 
in this study. All participants gave their written informed consent, which was approved by the local Ethics Committee of the (omitted for review).

\subsection{Task and Apparatus}

The task consisted of throwing darts with the dominant hand, aiming to hit the center of a circular target positioned at eye level for the participant. Specifically, participants were required to use the "common" or "pen" grip to throw a $20 \mathrm{~g}$ XL dart (Unicorn Products Ltd., England) at a target with a diameter of $432 \mathrm{~cm}$ (Pro-Shot Dart board—Leisure Time Products Ltd.-UK).

\subsection{Procedures and Design}

The experiment consisted of two phases named "Acquisition” (AQ) and "Retention” (RT). Before starting the experiment, participants were randomly assigned to four groups of random practice and four groups of blocked practice. Each of these four groups $(n=18)$, within each practice schedule, was assigned to take the RT 10 minutes (blocked: BL10, random: RD10), 24 hours (blocked: BL24, random: RD24), 7 days (blocked: BL7, random: RD7) or 30 days (blocked: BL30, random: RD30) after the AQ.

In the acquisition phase, participants in blocked groups performed three blocks of 30 trials, with each block consisting of throwing the darts from one of three distances $(2 \mathrm{~m}, 2.6 \mathrm{~m}$ and $3.2 \mathrm{~m}$, respectively). The distances' order were counterbalanced across participants. Under random practice, the trial order was pseudo-randomized, so that one given distance was not repeated in successive trials. The radial distance from the dart to the inner bull was measured and registered by the experimenter after three consecutive throws.

Participants watched a video of an expert performing the task before the experiment started. They were instructed to stand with their shoulders forming an angle of approximately $90^{\circ}$ with the board, so that their front leg corresponded to the throwing hand. His or her foot should touch the line on the floor- that indicated the distance from the board - so that it formed an angle of $45^{\circ}$ with respect to the board; the upper arm should be parallel to the ground with the joints (shoulder and elbow) flexed to $90^{\circ}$; the dart should point at the target and the eye should remain open during execution; the throw should be made by moving only the forearm and the fingers should point to the target after the throw. These instructions were also provided before the 31st and 61st trials. No instruction was provided during the RT, which consisted of performing 18 trials from the distance of $2.6 \mathrm{~m}$.

\subsection{Data Analysis}

With regard to the AQ, the root mean square of the radial error (RMS) over 9 trials (90 total—10 blocks of 9 trials), was the dependent measure of interest. RMS in the AQ was submitted to two-way ANOVA (Blocked and Random groups x 10 blocks), with repeated measures on the second factor, for each retention interval separately. The RT test was analyzed in two blocks of 9 trials each. RMS in the RT was submitted to two-way ANOVA (Blocked and Random groups x 2 blocks) with repeated measures on the second factor, for each retention interval separately. Departures from sphericity were verified through the Mauchley's test and the GreenhouseGeisser's method was used to correct the degrees of freedom when necessary. Differences between Blocked and Random groups were further assessed through pairwise t-tests using the FDR (False Discovery Rate) correction (Benjamini \& Hochberg, 1995). The data were organized, analyzed and plotted using R, a language and environment for statistical computing (R Core Team, 2013).

\section{Results}

\subsection{Acquisition}

Figure 1 shows the RMS for each block of trials during the AQ and the RT, grouping blocked and random groups according to the interval in which they were tested. No differences between Blocked and Random groups were found in the AQ, 10 minutes: $\mathrm{F}(1,34)=1.37, p>.05, \eta^{2}{ }_{\mathrm{G}}=.01 ; 7$ days: $\mathrm{F}(1,34)=2.93, p>.05$, $\eta^{2}{ }_{\mathrm{G}}=.02 ; 30$ days: $\mathrm{F}(1,34)=.1, p>.5, \eta^{2}{ }_{\mathrm{G}}=.001$, except for an interaction between groups and blocks of trials, 24 hours: $\mathrm{F}(1,34)=2.08, p<.05, \eta_{\mathrm{G}}{ }^{2}=.02$, indicating that participants in Blocked and Random groups, scheduled to be tested 24 hours after the AQ, showed different progression during practice-Mauchly's test indicated that the assumption of sphericity had been violated ( $\mathrm{W}=.18, p<.05)$, thus Greenhouse- 
Geisser estimates of sphericity were used $(\varepsilon=.73)$. The post hoc test indicated that, although both groups showed significant improvement of performance over the AQ (group BL24 showed higher RMS in block 1 compared to blocks 4 to 10; in block 2 compared to blocks 7 to 10; in block 3 compared blocks 7, 8 and 10; in block 4 compared to blocks 7 and 10; and in block 5 and 6 compared to block 7-group RD24 showed higher RMS in block 1 compared to blocks 4, 5 and 8 to 10; and in block 2 compared to blocks 4,5 and 7 to 10 ), the group BL24 performed better in the block 7, compared to the group RD24. The other groups showed significant improvement of performance during the AQ, indicated by the main effect of blocks, 10 minutes: $\mathrm{F}(9,306)=7.32, p<.01, \eta^{2}{ }_{\mathrm{G}}=.1 ; 7$ days: $\mathrm{F}(9,306)=3.34, p<.01, \eta_{\mathrm{G}}{ }_{\mathrm{G}}=.06 ; 30$ days: $\mathrm{F}(9,306)=7.19, p$ $<.01, \eta^{2}{ }_{G}=.1-$ Greenhouse-Geisser estimates of sphericity were used to correct the degrees of freedom: 10 minutes $(\varepsilon=.55), 7$ days $(\varepsilon=.46)$ and 30 days $(\varepsilon=.62)$. Post hoc analysis determined that participants scheduled to be tested 10 minutes after the AQ (groups BL10 and RD10) showed higher RMS in block 1 compared to blocks 3 and 5 to 10; in block 2 compared to blocks 5 and 8 to 10; in block 3 compared block 9; and in block 4 compared to blocks 9 and 10. Participants in the groups BL7 and RD7 showed higher RMS in block 2 compared to block 9. Participants in the groups BL30 e RD30 showed higher RMS in block 1 compared to blocks 2 to 10; in blocks 2, as well as in block 3, compared to blocks 8 and 10; and in block 9 compared to block 8.

\subsection{Retention}

The repeated measures ANOVA on the RMS revealed significant effect of blocks for the groups tested 10 minutes, $\mathrm{F}(1,34)=4.16, p<.05, \eta_{\mathrm{G}}{ }=.02$, and 30 days after the $\mathrm{AQ}, \mathrm{F}(1,34)=12.62, p<.01, \eta^{2}{ }_{\mathrm{G}}=.09$, indicating improvement of performance during the retention test. There was also a significant effect of group, establishing that participants undergoing blocked and random practice differed in retention when tested $24 \mathrm{~h}$ after the AQ, $\mathrm{F}(1,34)=5.41, p<.05, \eta_{\mathrm{G}}^{2}=.11$. This result supports our prediction that an "adequate" period of time is needed so that the contextual interference effect can be observed.

\section{Discussion}

The goal of the experiment we report here was to determine whether groups undergoing practice schedules with high and low contextual interference would show different performance in a retention test, depending on the amount of time separating the AQ and the test itself.

In relation to the AQ, random groups achieved descriptively higher RMS than blocked groups after the block 6 (Figure 1) - except for the group scheduled to be tested 10 minutes after the AQ, that showed similar performance with its respective blocked group. Although performance decrements, accompanying variations, are expected in the AQ (e.g. Magill \& Hall, 1990) the only difference found between random and blocked groups was an interaction between blocks and groups for BL24 and RD24, indicating a worst performance of the group RD24 in one block of trials. These results suggest that blocked and random groups had similar performances over the AQ.

With respect to the retention tests, results clearly indicate superior performance of the random group, compared to the blocked group, in the RT carried out after $24 \mathrm{~h}$. As the main hypothesis was that more permanent internal representation would be build up with higher contextual interference, we expected to observe a better performance of the random practice groups also in the 7-day and 30-day RT. This result indicates that even though there are learning benefits associated to the practice with higher contextual interference, these benefits do not seem to be protected from forgetfulness. Thus, our results do not support the notion that under higher contextual interference internal representations are built up in a way that favors long-term retention. Nevertheless, further research is needed to investigate the processes underlying the effect, since short-term gains (24 h) were found.

The action plan reconstruction hypothesis (Lee \& Magill, 1983, 1985) states that practicing under contextual interference benefits learning by demanding higher cognitive effort, since information would be forgotten completely or partially. Nevertheless, the cognitive effort afforded by the random practice-predicted to occur between trials by the "elaboration and distinction" and the "action plan reconstruction" hypotheses (see also Lee, Swinnen, \& Serrien, 1994) — should not be considered alone. If the cognitive effort sufficed for the contextual interference effect, the random group tested 10 minutes after the acquisition phase would have shown better performance than the blocked group. Thus, it is critical to consider that the processes initiated by practicing a 


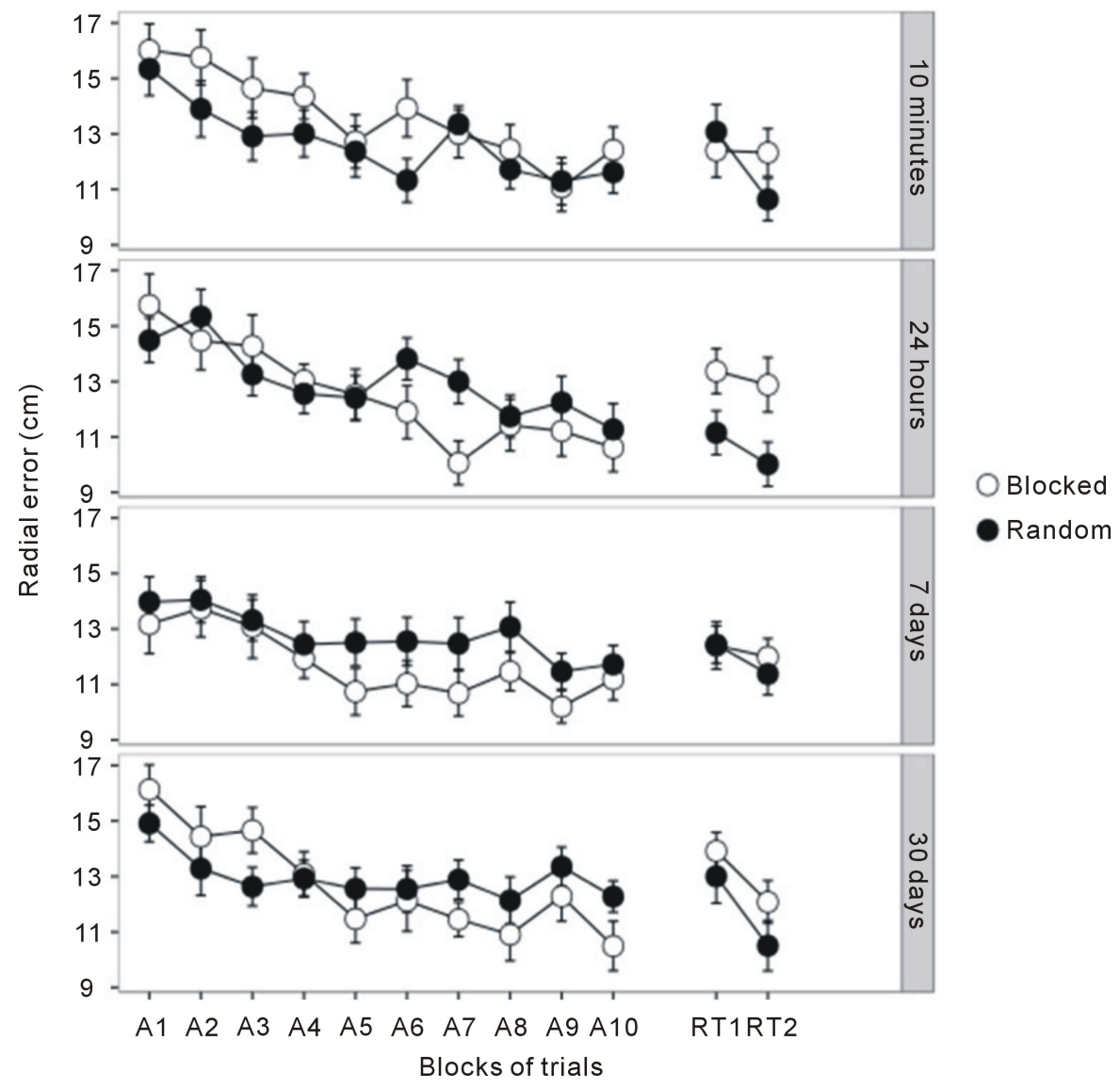

Figure 1. Root mean square of the radial error of blocked and random groups. A1 - A10 refer to the blocks of trials of the Acquisition and RT1 and RT2 to the blocks of trials of the retention test. Blocked and random groups are grouped according to the interval in which they were tested (10 minutes, 24 hours, 7 days and 30 days). Error bars represent the \pm SEM.

motor skill continues after the practice has ended (e.g. Kantak et al., 2010). In this sense, our results give support to the notion of memory consolidation (Brashers-Krug, Shadmehr, \& Bizzi, 1996; Stickgold, 2013 for a review), indicating that the practice with higher contextual interference enhances the referred processes, compared to the practice with lower contextual interference.

In relation to the time needed to observe a beneficial effect of a more varied practice, a recent study from our research group (Bastos, Marinovic, De Rugy, \& Tani, 2013) showed performance gains in tests conducted immediately and 15 minutes after the acquisition phase (AQ). The task consisted of pressing the space bar of a computer keyboard at the exact time a moving target would make contact with a stationary target, positioned at the right side of a monitor screen. Participants could choose, before each trial, the velocity of the moving target, among three possible ones. Additionally to the task goal, one of the groups received also a "learning goal", an information about the context in which the sensorimotor skill would be performed. Specifically, participants were informed that they should select the velocities during the AQ in order to prepare for a test in which the three velocities of the target would be arranged randomly. The results indicated that participants given prior knowledge of final testing performed better in both, immediate and delayed (15 minutes) test. Although these participants varied more over the AQ, the practice schedule resulting from their choices was not "purely" blocked or random, but a combination of them. The authors proposed that those who received the learning goal performed some consecutive trials of a given velocity to optimize their performance on that velocity, despite being aware that they should vary to prepare for the test. This resulting practice schedule benefited not only the participants allowed to choose among velocities, but also a mirrored (yoked) group. As in the present study more time was needed to observe a difference among groups underlying more and less varied practice ( $24 \mathrm{~h}$, compared 
to the immediate and 15 minutes interval employed by Bastos et al., 2013), one could suppose that this "combined practice" affects the time needed for motor memory consolidation. Nevertheless, this issue remains open and should be tackled in future studies.

Based on our results, one could argue that if the task continued to be practiced by two random groups through more than two sessions, one of them scheduled to practice across consecutive days and the other one scheduled to practice the same amount of practice trials within a day, the one practicing across days would benefit from the contextual interference effect. Although this specific question is still open (to our best knowledge), the effect of spacing practice sessions across days compared to spacing sessions within a day was already investigated (Shea, Lai, Black, \& Park, 2000). In this study, participants practiced a balance task on a stabilometer for two sessions, each consisting of seven 90 seconds practice trials. While one of the groups performed both practice sessions on the same day, separated by a 20 minutes interval, the other group practiced for one session on each of two consecutive days. Both groups were tested - retention test-24 h after the end of the acquisition phase, revealing a better performance of the group practicing across days. In a subsequent experiment, the authors tested whether the results of the first experiment could be generalized to a discrete task-a sequence of key presses on a numeric keyboard. Interestingly, in this experiment, three movement sequences were practiced in a blocked practice schedule, so that participants with sessions spaced across days performed all trials of a given sequence in one day-resulting in three consecutive days of practice. Again, the results showed a better performance of the group practicing across days, compared to the group with sessions separated by 10 minutes. Considering the learning gains obtained by spacing blocked practice across days-i.e. separated by a $24 \mathrm{~h}$ interval)—and our results indicating the necessity of $24 \mathrm{~h}$ interval for the benefits of random practice (contextual interference effect), future research should consider investigating whether spacing random practice across days would lead to superior learning gains when compared to those obtained by similarly spacing a blocked practice schedule

\section{Conclusion}

In this report we have demonstrated that the time interval separating the acquisition phase and the retention test is critical to observe the contextual interference effect. Even though our results do not support the notion that higher contextual interference promotes immediate learning benefits or long-term retention of internal representations, future research should further investigate the processes underlying the effect, since short-term gains (24 h) were found. Moreover, our findings might guide professionals who work with motor learning, such as physical educators and physiotherapists, suggesting that people might benefit from practice with higher contextual interference if the amount of time separating the practice sessions is $24 \mathrm{~h}$. This issue, however, still needs further investigation.

\section{References}

Albaret, J. M., \& Thon, B. (1998). Differential Effects of Task Complexity on Contextual Interference in a Drawing Task. Acta Psychologica, 100, 9-24. http://dx.doi.org/10.1016/S0001-6918(98)00022-5

Barreiros, J., Figueiredo, T., \& Godinho, M. (2007). The Contextual Interference Effect in Applied Settings. European Physical Education Review, 13, 195-208. http://dx.doi.org/10.1177/1356336X07076876

Bastos, F. H., Marinovic, W., De Rugy, A., \& Tani, G. (2013). Prior Knowledge of Final Testing Improves Sensorimotor Learning through Self-Scheduled Practice. Human Movement Science, 32, 192-202. http://dx.doi.org/10.1016/j.humov.2012.11.008

Benjamini, Y., \& Hochberg, Y. (1995). Controlling the False Discovery Rate: A Practical and Powerful Approach to Multiple Testing. Journal of the Royal Statistical Society: Series B (Methodological), 57, 289-300.

Boutin, A., \& Blandin, Y. (2010). Cognitive Underpinnings of Contextual Interference during Motor Learning. Acta Psychologica, 135, 233-239. http://dx.doi.org/10.1016/j.actpsy.2010.07.004

Brashers-Krug, T., Shadmehr, R., \& Bizzi, E. (1996). Consolidation in Human Motor Memory. Nature, 382, $252-255$. http://dx.doi.org/10.1038/382252a0

Corrêa, U. C., \& Tani, G. (2005). Practice Structure and Adaptive Process in Motor Learning: For a New Approach of Practice. In Motor Behavior: Learning and Development (pp. 141-161). Rio de Janeiro: Guanabara Koogan.

Guadagnoli, M. A., \& Lee, T. D. (2004). Challenge Point: A Framework for Conceptualizing the Effects of Various Practice Conditions in Motor Learning. Journal of Motor Behavior, 36, 212-224. http://dx.doi.org/10.3200/JMBR.36.2.212-224 
Kantak, S. S., Sullivan, K. J., Fisher, B. E., Knowlton, B. J., \& Winstein, C. J. (2010). Neural Substrates of Motor Memory Consolidation Depend on Practice Structure. Nature Neuroscience, 13, 923-925. http://dx.doi.org/10.1038/nn.2596

Lee, T. D., \& Magill, R. A. (1983). The Locus of Contextual Interference in Motor-Skill Acquisition. Journal of Experimental Psychology: Learning, Memory, and Cognition, 9, 730-746. http://dx.doi.org/10.1037/0278-7393.9.4.730

Lee, T. D., \& Magill, R. A. (1985). Can Forgetting Facilitate Skill Acquisition? In R. B. W. and I. M. F. David Goodman (Org.), Advances in Psychology (Vol. 27, pp. 3-22). North-Holland. http://dx.doi.org/10.1016/S0166-4115(08)62528-5

Lee, T. D., Swinnen, S. P., \& Serrien, D. J. (1994). Cognitive Effort and Motor Learning. Quest, 46, 328-344. http://dx.doi.org/10.1080/00336297.1994.10484130

Lee, T. D., \& Weeks, D. J. (1987). The Beneficial Influence of Forgetting on Shorterm Retention of Movement Information. Human Movement Science, 6, 233-245. http://dx.doi.org/10.1016/0167-9457(87)90014-5

Magill, R. A., \& Hall, K. G. (1990). A Review of the Contextual Interference Effect in Motor Skill Acquisition. Human Movement Science, 9, 241-289. http://dx.doi.org/10.1016/0167-9457(90)90005-X

Massigli, M., Nunes, M. E. de S., Freudenheim, A. M., \& Corrêa, U. C. (2011). Practice Structure and Ecological Validity on the Adaptive Process of Motor Learning. Revista Brasileira de Educação Física e Esporte, 25, 39-48.

Moreno, F. J., Avila, F., Damas, J., García, J. A., Luis, V., Reina, R., \& Ruíz, A. (2003). Contextual Interference in Learning Precision Skills. Perceptual and Motor Skills, 97, 121-128. http://dx.doi.org/10.2466/pms.2003.97.1.121

Naimo, M. A., Zourdos, M. C., Wilson, J. M., Kim, J.-S., Ward, E. G., Eccles, D. W., \& Panton, L. B. (2013). Contextual Interference Effects on the Acquisition of Skill and Strength of the Bench Press. Human Movement Science, 32, $472-484$. http://dx.doi.org/10.1016/j.humov.2013.02.002

Ollis, S., Button, C., \& Fairweather, M. (2005). The Influence of Professional Expertise and Task Complexity upon the Potency of the Contextual Interference Effect. Acta Psychologica, 118, 229-244. http://dx.doi.org/10.1016/j.actpsy.2004.08.003

Porter, J. M., \& Magill, R. A. (2010). Systematically Increasing Contextual Interference Is Beneficial for Learning Sport Skills. Journal of Sports Sciences, 28, 1277-1285. http://dx.doi.org/10.1080/02640414.2010.502946

R Core Team (2013). R: A Language and Environment for Statistical Computing (Version 3.0.2). Vienna: R Foundation for Statistical Computing.

Shea, C. H., Lai, Q., Black, C., \& Park, J.-H. (2000). Spacing Practice Sessions across Days Benefits the Learning of Motor Skills. Human Movement Science, 19, 737-760. http://dx.doi.org/10.1016/S0167-9457(00)00021-X

Shea, J. B., \& Morgan, R. L. (1979). Contextual Interference Effects on the Acquisition, Retention, and Transfer of a Motor Skill. Journal of Experimental Psychology: Human Learning and Memory, 5, 179-187. http://dx.doi.org/10.1037/0278-7393.5.2.179

Shea, J. B., \& Wright, D. L. (1991). When Forgetting Benefits Motor Retention. Research Quarterly for Exercise and Sport, 62, 293-301. http://dx.doi.org/10.1080/02701367.1991.10608726

Shea, J. B., \& Zimny, S. T. (1983). Context Effects in Memory and Learning Movement Information. In R. A. Magill (Org.), Advances in Psychology (Vol. 12, pp. 345-366). North-Holland. http://dx.doi.org/10.1016/S0166-4115(08)61998-6

Silva, J. A. de O., Araujo, U. O., Tani, G., \& Corrêa, U. C. (2009). Practice Schedule and Task Complexity on the Adaptive Process of Motor Learning. Revista da Educação Física/UEM, 20, 313-323. http://dx.doi.org/10.4025/reveducfis.v20i3.6881

Souza, T. O., Santos, J. J., Torriani-Pasin, C., \& Corrêa, U. C. (2013). O efeito da interferência contextual na aquisição de habilidades motoras e as dificuldades funcional e nominal da tarefa. Motricidade, 9, 57-69. http://dx.doi.org/10.6063/motricidade.9(3).763

Stickgold, R. (2013). Parsing the Role of Sleep in Memory Processing. Current Opinion in Neurobiology, 23, 847-853. http://dx.doi.org/10.1016/j.conb.2013.04.002

Travlos, A. K. (2010). Specificity and Variability of Practice, and Contextual Interference in Acquisition and Transfer of an Underhand Volleyball Serve. Perceptual and Motor Skills, 110, 298-312. http://dx.doi.org/10.2466/pms.110.1.298-312

Wright, D. L. (1991). The Role of Intertask and Intratask Processing in Acquisition and Retention of Motor Skills. Journal of Motor Behavior, 23, 139-145. http://dx.doi.org/10.1080/00222895.1991.9942031

Wright, D. L., Li, Y., \& Whitacre, C. (1992). The Contribution of Elaborative Processing to the Contextual Interference Effect. Research Quarterly for Exercise and Sport, 63, 30-37. http://dx.doi.org/10.1080/02701367.1992.10607554

Wrisberg, C. A., \& Liu, Z. (1991). The Effect of Contextual Variety on the Practice, Retention, and Transfer of an Applied Motor Skill. Research Quarterly for Exercise and Sport, 62, 406-412. http://dx.doi.org/10.1080/02701367.1991.10607541

Wu, W. F. W., Young, D. E., Schandler, S. L., Meir, G., Judy, R. L. M., Perez, J., \& Cohen, M. J. (2011). Contextual Interference and Augmented Feedback: Is There an Additive Effect for Motor Learning? Human Movement Science, 30, 1092- 
1101. http://dx.doi.org/10.1016/j.humov.2011.02.004

Yanci, J., Reina, R., Los Arcos, A., \& Camara, J. (2013). Effects of Different Contextual Interference Training Programs on Straight Sprinting and Agility Performance of Primary School Students. Journal of Sports Science \& Medicine, 12, 601607. 